\title{
Hereditary neurocutaneous angioma: a new genetic entity?
}

\author{
J. ZAREMBA, MARIA STEPIEŃ, MARIA JELOWICKA, AND \\ DANUTA OSTROWSKA
}

From the Neurological Ward of the Psychiatric Hospital, Pruszków; and the Department of Genetics and Neuropathology, Psychoneurological Institute, Warsaw, Poland

SUMMARY A family pedigree with a possible new genetic syndrome characterised by the presence of angiomas, systemic in nature, affecting particularly the skin and the central nervous system, is described. Angiomas of the CNS seem to have a marked tendency to bleed. The condition shows a clearly dominant mode of transmission, four subjects in three generations being affected.

Differentiation from other conditions belonging to the vascular abnormalities subgroup of phakomatoses is presented.

Most cases of vascular malformation, apart from several well known genetic conditions, occur sporadically and do not seem to be genetically determined. Familial cases of syndromes like those of Sturge-Weber, Klippel-Trénaunay-Weber, and Bonnet-Dechaume-Blanc, as well as other forms of angiomatous changes, are exceptional.

This was the main reason for describing a family in which angiomatous changes, not consistent with any recognised genetic syndrome, seem to show clear-cut Mendelian inheritance. The pedigree is shown in Fig. 1.

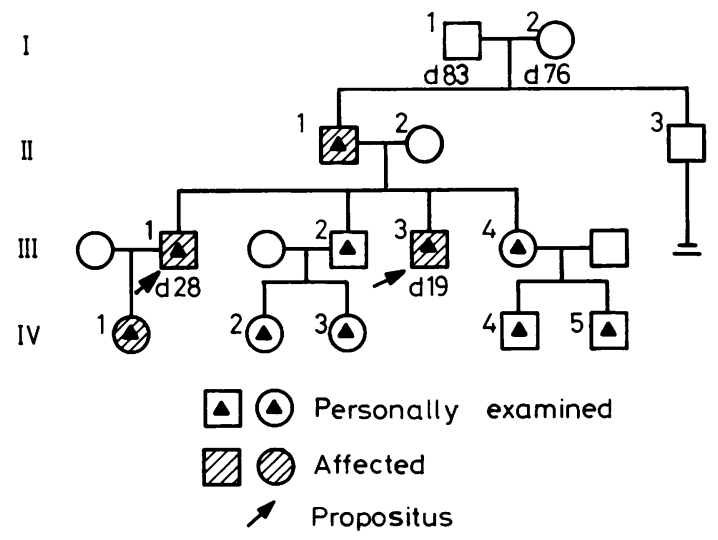

Fig. 1 Pedigree of family with hereditary neurocutaneous angioma.

Received for publication 20 January 1979

\section{Case reports and family data}

III.1 (EW) was born in 1945. At the age of 28 he was admitted to the neurological ward with a clinical picture of cerebral stroke. He had very intense and rapid onset headaches followed by loss of consciousness and left sided hemiparesis. For several years the patient suffered from headaches and had a tendency to nosebleeds.

On admission he was in deep coma with hemiplegia and signs of meningeal irritation. On the skin of the left shoulder, arm, and forearm there was an extensive, irregularly-shaped, pink haemangioma planum which faded on pressure. The eye fundi were normal. There were large amounts of blood components in the cerebrospinal fluid: 380000 red cells $/ \mathrm{mm}^{3}$, protein $7 \cdot 5 \mathrm{~g} / \mathrm{l}$. The general condition of the patient was so poor that he was not taken to the neurosurgical department situated in another town. Cerebral angiography was not performed for the same reason. The patient died 7 days after admission. At necropsy bilateral pneumonia and pulmonary oedema were found. There was also steatosis of the cardiac muscle.

Macroscopically, the brain showed a large haemorrhagic focus in the white matter of the right frontal and parietal lobes, extending into the lateral ventricle (Fig. 2). In the vicinity of the haemorrhagic focus, as well as inside it, circular outlines apparently formed by dilated vessels could be seen.

Microscopically, in the tissue adjacent to the haemorrhagic focus, multiple cross-sections of the large vessels could be seen (Fig. 3). The walls of the 


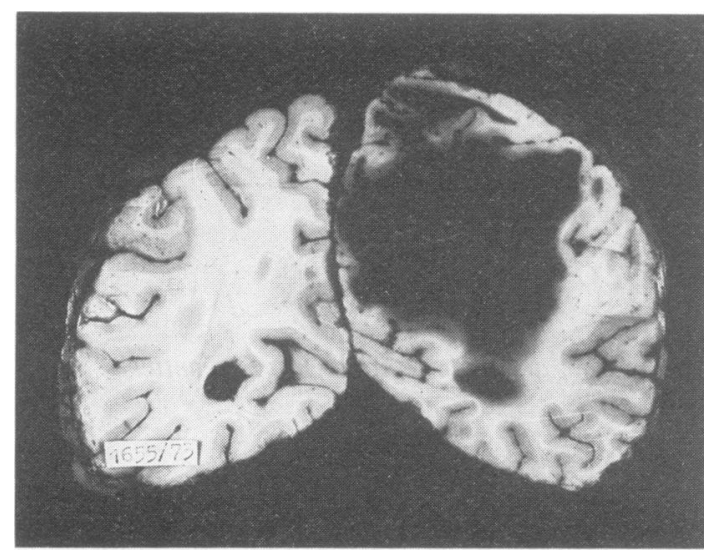

Fig. 2 Large haemorrhage into white matter of right cerebral hemisphere (III.I).

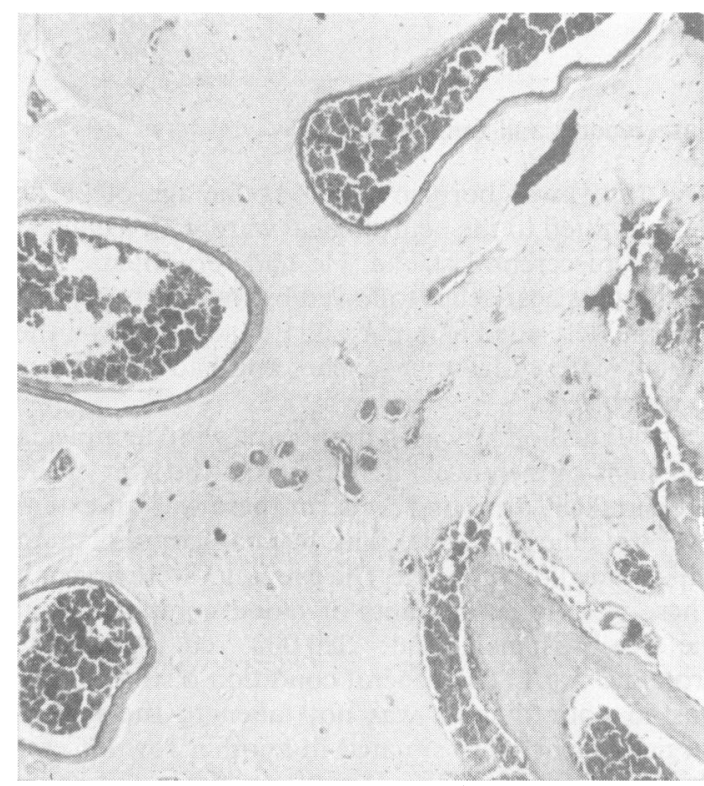

Fig. 3 Multiple abnormal vessels in the vicinity of haemorrhagic focus; vessels with large lumen and thin wall with elastic membrane present; vessels with thick collagenised, homogeneous wall; groups of minute vessels, their walls composed entirely of endothelial cells. (Resorcin-fuchsin. Original magnification $\times 30$.)

vessels were clearly abnormal: dilated veins with very thin walls, thin-walled arteries, as well as vessels with very thickly collagenised walls could be seen. Some of the vessels showed marked irregularities in the thickness of the walls. They were composed of three coats. However, elastic membrane did not form a uniform strip; in some places it w absent, in some reduplicated (Fig. 4). Thus, some $\frac{\text { क् }}{4}$ the abnormal vessels could be considered to be transitional between veins and arteries and we possibly shunts. Among the larger vessels, there were also groups of minute, thin-walled vessels wi walls composed entirely of endothelium (Fig. 30 Clusters of vessels in the subarachnoid space we composed mainly of normal veins and arteries However, vessels with thickened walls out of proportion to their lumen could also be seen there (Fig. 5).

III.3 $(G W)$ was born in 1953. At the age of years, in July 1966, he was admitted for the first time to the neurological ward because of left sided hen $\vec{P}$ paresis. Three weeks before admission he started to complain of pains in the left shoulder which gradually involved the whole left upper limb Paresis of the limb followed after a few days, at firs involving only the distal part of the extremity ane then spreading proximally.

Examination showed two skin angiomas, one in the left frontotemporal area and the other over the

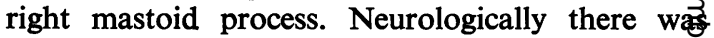
slight rigidity of the neck and dilation of the lef pupil. The limbs of the left side were thinner, theg difference in circumference being up to $1.5 \mathrm{cng}$

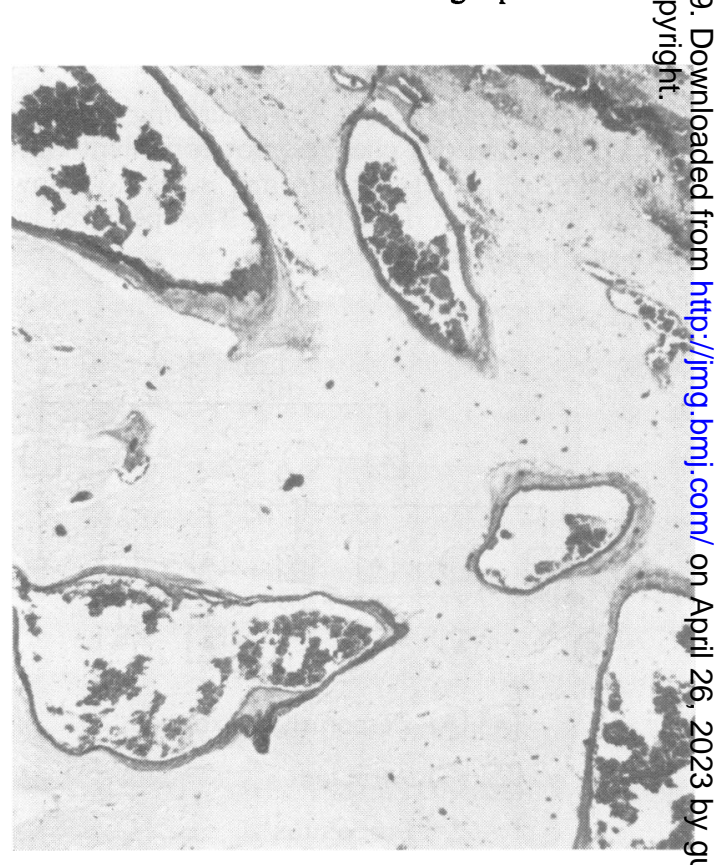

Fig. 4 Abnormal vessels: walls irregular in thickness with elastic membrane in some places reduplicated. Margin of haemorrhagic focus in right upper corner (Resorcin-fuchsin. Original magnification $\times 30$.) 


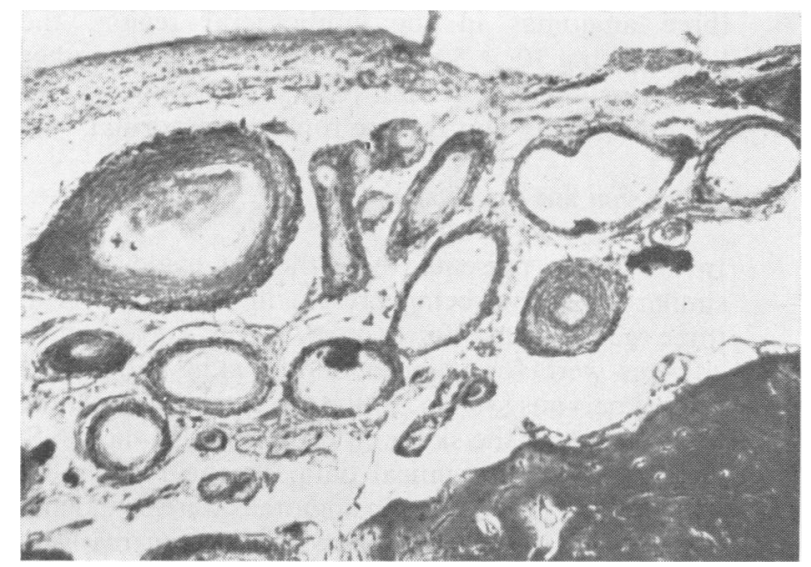

Fig. 5 Multiple sections of vessels in subarachnoid space, mostly having the appearance of normal veins and arteries. Those with thickened walls are of transitional character. (Perdrau. Original magnification $\times 30$.)

the upper limbs and $2 \mathrm{~cm}$ in the lower limbs. Paresis involved limbs of the left side. Eye fundi were normal. Cerebrospinal fluid was slightly xanthochromic, containing red blood cells $96 / \mathrm{mm}^{3}$, other cells $10 / \mathrm{mm}^{3}$, protein $0.9 \mathrm{~g} / 1$. Electroencephalogram showed no focal abnormalities.

The condition of the patient gradually improved and most of the neurological signs receded. Two subsequent lumbar taps showed that the CSF had returned to normal. $X$-rays of the vertebral column were normal.

Six months later (February 1967) he was admitted for the second time because of paresis of the right leg and pains in both left limbs. Examination showed increased perspiration on the left side of the face and a systolic murmur over the heart. Neurologically, there was Horner's syndrome on the right, distal paresis of the right upper limb with tendon reflexes more pronounced on the left side, abdominal reflexes diminished on the right side, paresis of the right lower limb with increased knee-jerk reflexes and absent ankle-jerk reflexes, and bilateral extensor plantar responses.

Initial examination of the CSF was normal. After a fortnight the condition of the patient deteriorated considerably. Paresis of the right lower limb became much more pronounced and was accompanied by disturbance of deep sensibility; superficial sensibility was diminished on the left side of the body below the level of $\mathrm{T} 1$. The above are signs of the Brown-Séquard syndrome. Moreover, the patient became incontinent of urine and faeces.

Examination of the CSF performed at that time showed xanthochromia, increase of protein content to $3 \mathrm{~g} / \mathrm{l}$, and red cells $17 / \mathrm{mm}^{3}$. The patient was transferred to the neurosurgical department with the diagnosis of angioma of the spine.

An operation was performed in March 1967.
Incision of the dura at the level of $\mathrm{C} 6$ to $\mathrm{T} 1$ showed a swollen and distended spinal cord. On the right side of the cord at the level of $\mathrm{T} 1$ the arterial vessels were tortuous and their number was increased. The tissues of the spine on the left side at the same level were xanthochromic. At the level of $\mathrm{C} 7$ the surface of the spine was bluish in colour. Longitudinal incision was performed at that level and a greyish-cherry coloured, tumourous, non-pulsating mass could be seen. It appeared to separate easily from the spinal tissue. Gripping at what appeared to be a capsule of the tumour caused violent arterial bleeding. Attempt at coagulation was not successful; the bleeding could be stopped only by tamponade. The removal of the angioma was considered not to be feasible. According to the neurosurgeon, the tumour was an arteriovenous intraspinal angioma which, judging by the history, caused two episodes of bleeding into the spinal cord.

After the operation, radiotherapy was administered. Neurologically, the patient had Horner's syndrome on the right, left-sided paresis of cranial nerves VII and XII, and paresis of both upper and lower limbs, more marked on the left side. The symptoms of the Brown-Séquard syndrome below C7 were present as before. Several months later the patient died at home. Necropsy was not performed.

\section{Other affected family members}

II.I $(J W)$, the father of the patients, was born in 1910. At 58 years of age he suddenly developed leftsided hemiparesis believed to be the result of cerebral haemorrhage. Between the ages of 64 and 66 he had frequent episodes of urinary bleeding. At 64 he also had an episode of bleeding from the digestive tract; he was then suspected of having cirrhosis of the liver. No further details were available. 


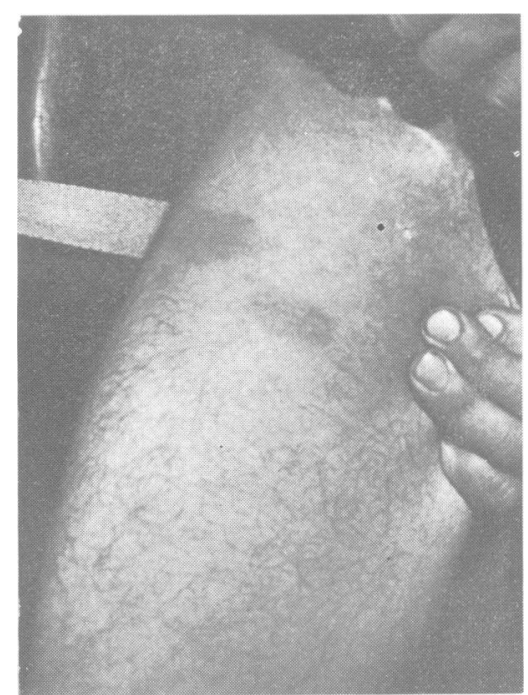

Fig. 6 Skin angiomas of left thigh in case II.1.

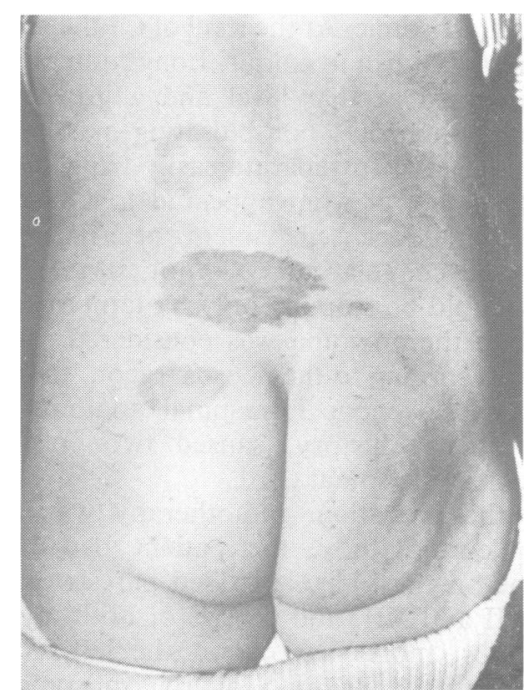

Fig. 7 Skin angiomas of lumbosacral region in case IV.1.

He was examined by the authors at the age of 64 . Several capillary angiomas of the skin were found, two on the chest $(1 \times 1 \mathrm{~cm}$ and $2 \times 1 \mathrm{~cm})$ and three on the medial aspect of his left thigh $(3 \times 3 \mathrm{~cm}$, $4 \times 2 \mathrm{~cm}$, and $1 \times 1 \mathrm{~cm}$ ) (Fig. 6). Neurologically, there was face and tongue weakness on the left, as well as left-sided mild spastic hemiparesis. Eye fundi were normal.

IV. $1(M W)$, daughter of III.1, was born in 1973 . She was seen by us at the age of 2 years. She had three angiomas in the lumbosacral region, th largest being $10 \times 5 \mathrm{~cm}$ (Fig. 7). There was anoth small angioma on her left palm. Otherwise she had no abnormality and the eye fundi were normal.

\section{Discussion and conclusions}

In the family presented here there is evidence of similar syndrome being present in four subjects three generations. In two of them, angiomatous changes were found both on the skin and in the central nervous system. In the third subject (II 1) the lesion involved the skin and probably also the CNS judging from the clinical data. In the fourth an youngest subject, only skin angiomas were found an there was no evidence of other organs being involve The distribution of the affected subjects in the pedigree (Fig. 1) is consistent with a dominant mode of transmission. The condition described needs differentiation from some well-known entities. shows some similarity to Rendu-Osler-Weber (ROW) hereditary haemorrhagic telangiectasia. The simi larities are as follows: dominant transmission an tendency to bleeding from mucous membran (present in our subjects III.1 and II.1). Moreove9. abnormalities of the larger vessels found in the brait of case III.1 seem to be similar to those presenf ig some cases of Rendu-Osler-Weber disease, eithe in the brain (Boczko, 1964; Arnould et al., 1969 or in other organs (Trell et al., 1972). The system nature of the lesions also are similar in both cond tions.

The skin lesions are entirely dissimilar in bo conditions: bleeding lesions of the mucous mer $\overrightarrow{3}$ branes typical of ROW disease were not found our cases. Another dissimilarity is the tendency of

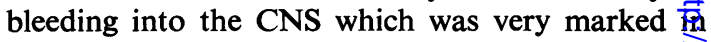
the cases described here, but is known to be rare ROW disease.

Another genetic condition which is similar in the vascular abnormalities and dominant inheritance Hippel-Lindau disease. Here, however, the blasto matous nature of vascular abnormalities, and the distribution in the CNS and other organs, obvious represent an entirely different type of lesion.

In Sturge-Weber syndrome, the site of the angio. mas and their appearance are quite different. $\overline{\mathrm{Ka}}$ this syndrome the angiomas are an intense bluishred, 'portwine', colour, whereas in our cases the were not so sharply delineated and rather pind This may be because of a preponderance of arterigl components in the naevi, compared to the SturgoWeber syndrome in which venous components predominate.

Intracranial calcifications characteristic of Sturge. Weber syndrome were not seen in the cases described 
here. Moreover, in most cases this syndrome is not familial but sporadic.

The Icelandic pedigree described by Kidd and Cumings (1947) is probably the one most similar to ours; ten subjects in the pedigree showed a tendency to cerebral haemorrhage apparently because of cerebral angiomas. In one case, necropsy data were available and angiomatous changes were found in the brain. In none of the cases, however, was the presence of skin angiomas reported.

Apart from the descriptions above, we could not find any cases similar to ours in published reports. Thus, it is possible that our cases may represent a new clinical and genetic entity.

The authors are grateful to Professor J. Dymecki, Psychoneurological Institute, for his help with histopathological data, to Dr Wieslawa Myga from the same Institute for examination of eye fundi of the affected subjects and other members of the family, to Dr J. Dobosz from the Psychiatric Hospital in Pruszków, who examined neurologically two of the affected subjects, and to Dr J. Dziduszko from the Department of Neurosurgery, Polish Academy of Sciences, who gave a description of neurosurgical procedure.

\section{References}

Arnould, G., Dureux, J. B., Tridon, P., Picard, L., Weber, M., Thiriet, M., and Floquet, J. (1969). Malformations vasculaires cérébrales et angiomatose de Rendu-Osler. Revue Neurologique, 119, 230-235.

Boczko, M. (1964). Neurologic implications of hereditary hemorrhagic telangiectasis. Nervous and Mental Disease, 139, 525-536.

Kidd, H. A., and Cumings, J. N. (1947). Cerebral angiomata in an Icelandic family. Lancet, 1, 747-748.

Trell, E., Johansson, B. W., Linell, F., and Ripa, J. (1972). Familial pulmonary hypertension and multiple abnormalities of large systemic arteries in Osler's disease. American Journal of Medicine, 53, 50-63.

Requests for reprints to Dr J. Zaremba, Department of Genetics, Sobieskiego 1/9, 02-957 Warsaw, Poland. 